\title{
ESCUELAS RURALES Y PRODUCCIÓN DEL ESPACIO. ALDEA ESCOLAR CHACAY OESTE, PROVINCIA DEL CHUBUT
}

\author{
Andrea Daniela Franco \\ Departamento de Geografía e Instituto de Investigaciones Geográficas de la Patagonia \\ (IGEOPAT), Facultad de Humanidades y Ciencias Sociales, Universidad Nacional \\ de la Patagonia San Juan Bosco. danielafranco@infovia.com.ar \\ Licenciada en Geografía de la Universidad Nacional de la Patagonia San Juan Bosco; \\ máster en Energías Renovables. Aplicación en el Ámbito Rural, de la Universidad \\ Internacional de Andalucía, sede La Rábida, España. Doctoranda en Geografía en la \\ Universidad Nacional del Sur. Docente-investigadora de la Universidad Nacional de \\ la Patagonia San Juan Bosco. Miembro del Comité Asesor del Instituto de Investiga- \\ ciones Geográficas de la Patagonia -IGEOPAT. FHyCS. UNPSJB.
}




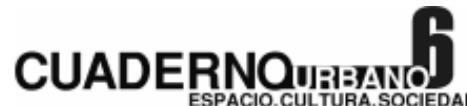

Escuelas ruRales y producción del espacio. Aldea escolar Chacay Oeste, Chubut

\section{Resumen}

Las escuelas rurales creadas en la meseta central de la provincia de Chubut dieron lugar al surgimiento de aldeas escolares, pequeños asentamientos temporarios formados por familias de productores ovinos y caprinos. El fin de las aldeas era que los niños de las familias rurales, que viven en unidades domésticas dispersas, tengan acceso a la educación formal.

Chacay Oeste surgió en 1922. Si bien nace con el fin de que las mujeres (mamás, hermanas, tías, abuelas) que tuvieran a su cargo niños en edad escolar permanecieran allí solamente durante el ciclo lectivo, a partir de 1999 comienza a transformarse en un asentamiento de características diferentes a las previstas en su surgimiento.

El trabajo aborda el rol de las escuelas rurales en la producción del espacio, tomando como estudio de caso Chacay Oeste. Para ello se analizaron entrevistas semi-estructuradas y observaciones directas realizadas en el período 2002-2005.

\begin{abstract}
The rural schools created in the central plateau of the province of the Chubut gave place to the sprouting of schools villages, small temporary establishments formed by families of ovine and goat producers. The aim of the villages was that the children of the rural families, who live in domestic dispersed units, have access to the formal education.

Chacay Oeste arose in 1922. Though it is born in order that the women (mothers, sisters, aunts, grandmothers) that they had children in school age were remaining there only during the school cycle, from 1999 it begins to transform in an establishment of characteristics different from the anticipated ones in his sprouting.

The work approaches the role of the rural schools in the production of the space, taking Chacay Oeste as a study of case. For it there were analysed semi-structured interviews and direct observations realized in the period 2002-2005.
\end{abstract}




\section{Andrea Daniela Franco}

Escuelas RuRales y producción del espacio. Aldea escolar Chacay Oeste, Chubut

\section{INTRODUCCIÓN}

Luego de la denominada conquista del desierto (1879-1885) la Patagonia fue incorporada a la República Argentina como un territorio nacional.

Dentro de las nuevas formas de relaciones sociales impuestas por la gradual presencia del Estado puede mencionarse la apropiación privada de los recursos naturales y la erradicación de la formas de religiosidad indígena para lo cual se insistió en la conversión de los pueblos originarios al catolicismo (Bandieri; 2005:146). Si bien esto último pone en evidencia que la dominación política fue acompañada por la conquista espiritual, en definitiva sería la educación la que terminaría por homogeneizar y argentinizar a los habitantes de los nuevos territorios nacionales.

Para ello en 1884 el Estado central impuso, a través de la ley 1420 de educación común (gratuita, obligatoria, graduada y laica), la escolarización de la población residente tanto en la Capital Federal como en los territorios nacionales. Bajo esta ley se articularon tanto las escuelas del Estado como las particulares de la Congregación Salesiana, presentes en la región desde 1880.

En este contexto, con el fin de brindar educación obligatoria a los hijos de los productores minifundistas residentes en las zonas de menor densidad demográfica, surgen las escuelas rurales. Alrededor de ellas fueron construyéndose ranchos de adobe donde se instalaban mujeres con niños en edad escolar. Éstos eran miembros de familias de productores minifundistas que criaban lanares y caprinos, tanto propios como ajenos, y realizaban además tareas extraprediales como alambrador o esquilador. Estos pequeños asentamientos temporarios son denominados aldeas escolares.

Los docentes, que venían de las provincias que contaban con profesorados de magisterio, fueron quienes motivaron la conformación de la aldea. Ellos instaban a la construcción de viviendas alrededor de la escuela donde se instalaban las mujeres y los niños, mientras que los padres continuaban viviendo en las unidades domésticas. 


\section{CUADERNO}

Escuelas ruRales y producción del espacio. Aldea escolar Chacay Oeste, Chubut

\section{1- Además de compleja es extraña dado que pertenecemos a un mundo de diferentes significados como es el mundo citadino.}

\section{ESCUELAS RURALES Y PRODUCCIÓN DEL ESPACIO}

El análisis de escuelas rurales requiere sumergirse en una trama compleja ${ }^{1}$ en la que se recrean diferentes contextos territoriales, donde la educación se presenta como un eje condicionado, por factores políticos y socio-económicos, y condicionante, de las producciones y reproducciones sociales y culturales que movilizan la construcción del territorio.

No nos explayaremos en los conceptos de espacio y territorio. Simplemente señalaremos que el territorio es el espacio con sentido. Tal sentido hace referencia a que está influido por las ideologías dominantes en determinado momento histórico y en relación con un proyecto, compartido colectivamente o no, pero hegemónico. Mientras que en el espacio, si bien se encuentran presentes tanto elementos fijos como flujos, no se identifican con un sentido hegemónico organizador u orientador. Igualmente tengamos presente que el pasaje del territorio al espacio y del espacio al territorio se da en forma ininterrumpida, ligado con la necesidad ineludible de crear sentido, no sólo en lo específicamente territorial, sino en relación con toda actividad humana (Bustos Cara; 1998).

De este modo, la educación, producto y parte de un sistema de masificación mayor, incide en las estructuras y relaciones que producen el territorio. Esto pone de manifiesto el poder de agilización o freno que puede significar la educación para los procesos de construcción cultural y territorial. (Franco; 2005)

En esa construcción tiene un lugar central el proyecto de los directivos y docentes. Es decir, las acciones de los sujetos no son aleatorias sino que responden al logro de objetivos. Los que estarán, en mayor o en menor medida y dependiendo del sujeto o grupo, sistematizados y concienciados. Pensemos que la acción de los sujetos en el espacio sólo es comprensible dentro de la matriz significante, en tanto proceso social, que la contiene y define como tal.

Entonces, la escuela es una productora de territorio ya que actúa en lo inmaterial y lo ideológico, para producir materialidad. Esta situación se potencia por su condición de institución, prácticamente única y solitaria, en extensos espacios rurales. 


\section{Andrea Daniela Franco}

Escuelas RuRales y producción del espacio. Aldea escolar Chacay Oeste, Chubut

Es preciso señalar que el término institución tiene tres acepciones, que aunque vinculadas íntimamente, refieren a cuestiones diferentes. (Rodríguez; 1996)

En primer lugar, el término alude a organizaciones concretas, como una escuela, en las que se cumplen ciertas funciones especializadas que tienen el propósito de concretar acciones-valores.

En segundo lugar, alude a normas que expresan valores altamente protegidos en una realidad social determinada, lo que hace que tenga alta vigencia en la vida cotidiana. Es decir, la institución es sinónimo de regularidad social. En este sentido es institución la norma social por la cual en una población rural el director de la escuela local forma parte del grupo de notables cuyo juicio marca dirección en las acciones de interés comunitario.

La tercera acepción liga al término institución con los significados. Es decir, al mundo simbólico que orienta al sujeto para entender y decodificar la realidad social.

De este modo, las tres acepciones del concepto institución se conjugan para dar lugar al establecimiento educativo rural, el cual cumplirá con el fin de brindar educación formal de acuerdo con los contenidos curriculares establecidos a nivel nacional y provincial. Pero al mismo tiempo se instituirán las normas necesarias y concordantes con los proyectos de los docentes.

Tengamos presente que en el territorio confluyen diferentes proyectos que, junto al hegemónico, se disputan el logro de sus objetivos.

\section{La aldea escolar en el contexto provincial}

La provincia de Chubut, al igual que el resto de las provincias patagónicas, se organizó económicamente en función de enclaves de utilización de recursos naturales. Un importante factor de asentamiento poblacional en las áreas rurales fue la actividad ovina, ya que integró a la región a la economía nacional y mundial a través de la exportación de 


\section{CUADERNO}

114

Escuelas rurales y producción del espacio. Aldea escolar Chacay Oeste, Chubut

2- División políticoadministrativa de las provincias de la República Argentina.

3- Según el Censo Nacional de Población, Vivienda y Hogares de

2001 - INDEC, la densidad demográfica de la provincia es de $1.84 \mathrm{hab} / \mathrm{km} 2$ y de los

departamentos de actividad agropecuaria es menor a $1 \mathrm{hab} /$

km2.

4- Como ejemplo puede señalarse que un poblador rural que vive con su familia en una unidad doméstica de la meseta chubutense manifestó que hacía dos años no iba a la localidad más cercana, una comuna rural de 500 habitantes.

Mapa 1. Ubicacion de la aldea escolar Chacay Oeste sus productos. El crecimiento ovino fue muy rápido hasta 1930, a partir de esa fecha se estancó o creció muy lentamente.

En los departamentos ${ }^{2}$ donde predomina la actividad agropecuaria, como los departamentos. Telsen y Gastre, la baja densidad ${ }^{3}$ poblacional es un rasgo característico al que se le suma la poca accesibilidad o inaccesibilidad en algunos casos a pueblos o ciudades ${ }^{4}$ debido, por un lado, a las características físicas del espacio donde viven: las grandes distancias, las condiciones climáticas, el estado de las vías de comunicación (rutas de ripio, huellas, caminos vecinales) y el tipo de medios de comunicación (vehículos — con muchos años de antigüedad y con poco mantenimiento-, caballos o de a pie), y por otro lado, las características culturales de la población que allí reside.

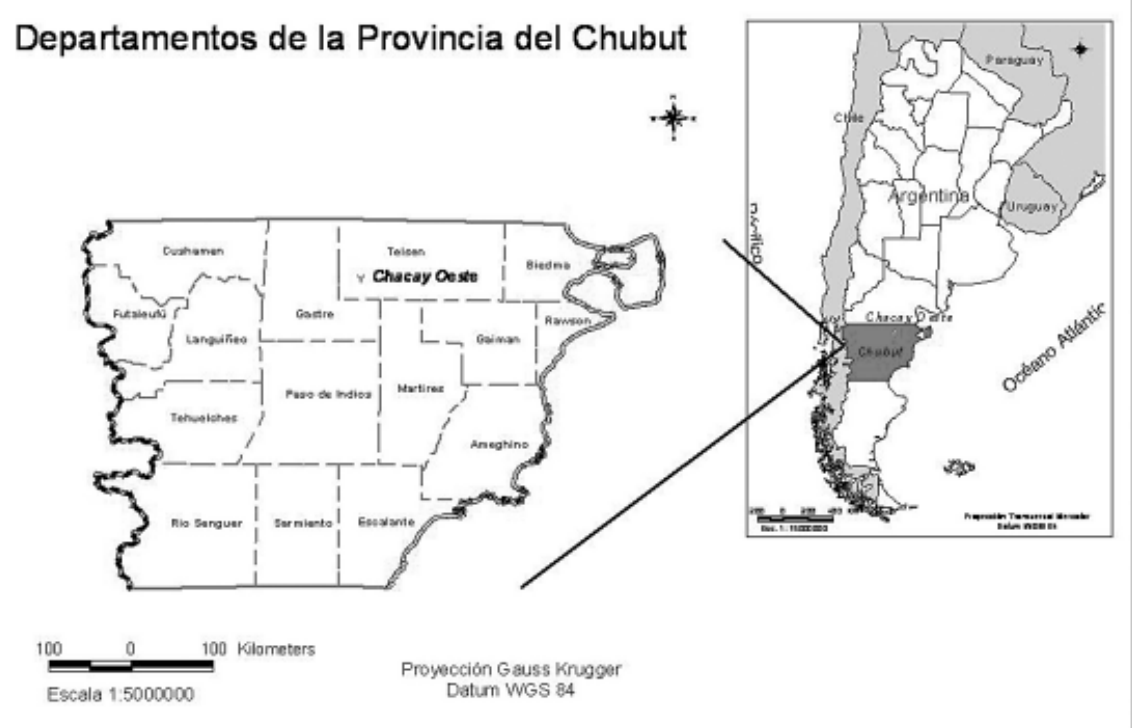




\section{Andrea Daniela Franco}

Escuelas RURALES Y PROdUCción del espacio. AldEA escolar Chacay Oeste, Chubut

Esta debilidad de la trama poblacional trae aparejado un alto grado de necesidades insatisfechas. Esto se debe a que la escasa cantidad de población no permite una economía de escala para la asistencia educativa y sanitaria. Además, las grandes distancias tornan imposible el tendido y mantenimiento de redes de servicios públicos de energía eléctrica, gas o teléfono, así como de la red vial que es fundamental en estos lugares.

Es en este contexto, la puesta en funcionamiento de la escuela y el posterior surgimiento de la aldea, más allá de lo político-ideológico, tiene una importante función social ya que es el espacio que posibilita el acceso a la educación formal a la población rural.

Las aldeas escolares dependen política y administrativamente de la comuna rural más cercana. En el caso de Chacay Oeste depende de Gan Gan. Es decir, el gobierno local está fuera de la aldea.

De este modo, las comunas y las aldeas son los núcleos poblacionales que brindan diferentes servicios a los residentes en las unidades domésticas cercanas. Si bien éstas últimas surgen con el sólo fin de brindar educación, en la actualidad en ellas se han instalado: puestos sanitarios, puestos policiales, iglesias, capillas o juzgados de paz y, en un caso excepcional, existe un comercio ${ }^{5}$. Estas instituciones no están presentes en todas las aldeas. Por ejemplo, Chacay Oeste cuenta con un puesto sanitario, una iglesia católica y un teléfono semi-público que funciona dentro del edificio escolar. La población, para poder satisfacer el resto de sus demandas, debe movilizarse hasta Gan Gan, a 30 km de distancia, o a la ciudad de Trelew, a $400 \mathrm{~km}$. (ver MAPA № 2)

Es importante señalar, en función de la distribución de los centros de servicios rurales, que las unidades productivas donde residen grupos domésticos dispersos se encuentran a importantes distancias, que van desde los $30 \mathrm{~km}$. hasta los $150 \mathrm{~km}$.

En la siguiente foto podemos observar que Chacay Oeste es un oasis de vegetación en un ambiente marrón-grisáceo. (Ver Foto l)

Entonces, podemos decir que las tareas pecuarias implican dispersión territorial y trabajo solitario, sobretodo en las pequeñas unidades domésticas. Esto sumado a la dispersión

- A pesar de que la ley de comercio prohíbe la instalación de comercios en un radio inferior a los $5 \mathrm{~km}$ de distancia de una escuela o una reserva aborigen. 
CUADER RSPACU,CULTURA,SOCIEDAD

116

Escuelas ruRales y producción del espacio. Aldea escolar Chacay Oeste, Chubut

Mapa 2. Ubicación de Chacay Oeste en el departamento Telsen

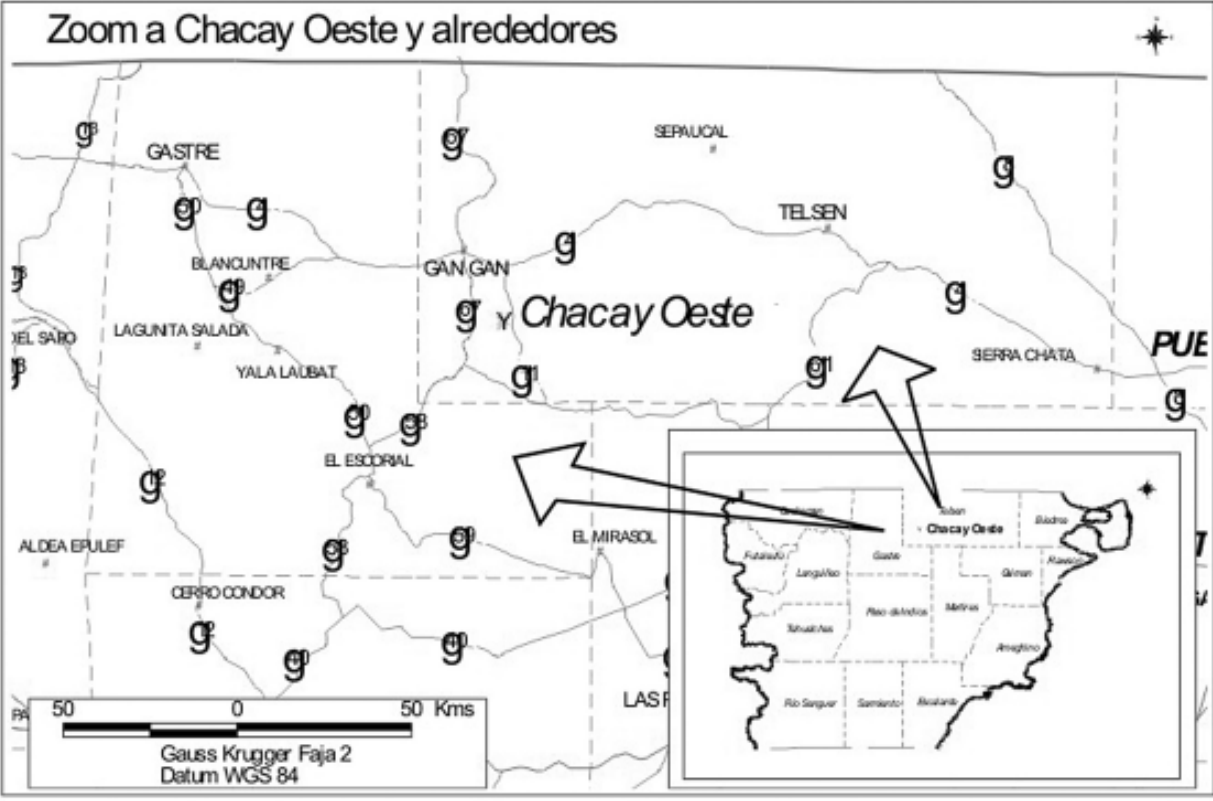

y marginación física hace que las unidades sean más vulnerables a las variables exógenas como: las características naturales del ambiente, las formas de comercialización (limitándolo al sistema del trueque y a quedar "atrapado" en manos del mercachifle o dueño del almacén de ramos generales), su localización geográfica, el sistema urbano y su articulación con los centros de servicios rurales. Si bien éstas son variables exógenas del entorno inmediato de Chacay Oeste son consecuencias de un modelo económico mundial, que privilegia aquellos lugares y actividades donde se logra una maximización de las ganancias en el corto plazo, y de las políticas económicas y sociales que él mismo genera y sustenta. 


\section{Andrea Daniela Franco}

Escuelas RuRales y producción del espacio. Aldea escolar Chacay Oeste, Chubut

La escuela rural del siglo pasado:

herramienta para la construcción del Estado nacional

La escuela 63, ubicada en lo que hoy se denomina aldea escolar Chacay Oeste, data de 1922. En sus inicios funcionó en la casa de un antiguo poblador del lugar. Conforme fueron aumentando los alumnos se construyó la escuela rancho que aún persiste y donde funciona una biblioteca popular. En 1975 se construyó el actual edificio.

Esta escuela comenzó siendo de personal único, pero en la actualidad el notable aumento de la matrícula ha llevado a que existan ocho docentes.

Los maestros provenían de provincias con tradición en docencia como San Luis, La Rioja, Entre Ríos, entre otras.

Con la firme convicción de cumplir con el objetivo que los había llevado hasta allí, educar a los niños de familias rurales dispersas, eran los mismos docentes quienes se encargaban de ir a buscar a los alumnos:

"Porque iban allá los maestros, agarraban un caballito, le pasaban un caballito ensillado y le decían que en tal parte había chicos y entonces iban allá (...) lo iban a buscar para que los traigan acá". (Exalumno de la escuela 63)

Una vez conformado el grupo de alumnos el docente debía ocuparse de otras actividades que hacían al funcionamiento de la escuela y del lugar. Un antiguo poblador señaló:

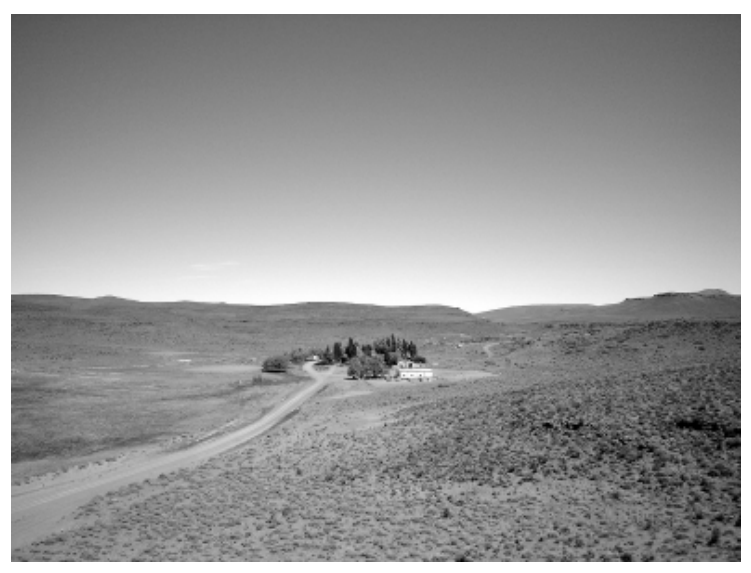

Foto 1. Vista panorámica de la aldea escolar Chacay Oeste 


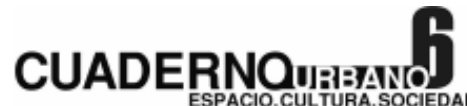

Escuelas ruRales y producción del espacio. Aldea escolar Chacay Oeste, Chubut

"Les hizo hacer casitas a los paisanos alrededor de la escuela entonces ahí las tenía a las familias, a la señora con los chicos" (supervisor del ex Consejo Provincial de Educación).

"La presencia ciertamente del maestro formando de alguna manera una comunidad" (ex-alumno de la escuela 63).

"Atendían a toda la comunidad, la escuela, el comedor, la salud, la justicia, por decir, el resolver los conflictos, la tensión. También con una mirada fuerte de fe que es la que los llevó a perseverar en la dificultad. Un hombre muy creyente. Él nos preparaba en la comunión" (ex-alumno de la escuela 63)

"De hecho, uno termina haciendo pensiones, planes jefas de hogar; cuando hay un nacimiento acompañar al juzgado, o sea un montón de cosas" (ex-docente de la escuela 63).

El relato, además de señalar que todas las tareas de la aldea estaban en manos del maestro, muestra algo muy importante: la presencia de otra institución muy fuerte como es la iglesia. De este modo se unen en una misma persona: el maestro y el religioso. Así, la comunión aparece vinculada con la educación y se trasforma en una norma que condiciona el funcionamiento del lugar.

Otra norma, pautada por el docente, era que los padres sólo podían visitar la aldea los fines de semana. Esta situación, más allá de que era necesaria para que la economía de subsistencia de estas familias no se profundizara, estaba contenida en un reglamento de convivencia elaborado por un docente que estuvo mucho tiempo en el lugar, alrededor de 30 años.

En ese reglamento se estipulaba lo siguiente:

* Las actividades que podían realizarse en las viviendas, prohibiéndose la realización de fiestas y bailes, recibir y alojar personas ajenas a la aldea, ingerir bebidas alcohólicas, llevar perros al lugar. 


\section{Andrea Daniela Franco}

Escuelas ruRales y producción del espacio. Aldea escolar Chacay Oeste, Chubut

* La ausencia de alumnos, motivada por la necesidad que colaboren con tareas de esquila de ovinos y caprinos o con el baño de la majada, debía informarse con anticipación.

* Se consideraba residentes de la aldea a: madres, hijos de corta edad y pre-escolar, escolares, ancianos, familiar a cargo del cuidado y responsabilidad de los niños.

* El padre o jefe del hogar era considerado residente transitorio ya que su presencia en la aldea escolar era justificada los fines de semana o días de semana cuando tenía que diligenciar asuntos personales en alguna institución o repartición pública de la zona o bien cuando su ausencia había sido prolongada.

* No se permitía la presencia de varones que no hicieran nada en su hogar ni prestasen en algún momento su colaboración con la escuela.

* Los ex-alumnos/as que deseaban continuar radicándose en la aldea escolar, podían justificarlo especificando el motivo por el que seguiría residiendo en el lugar, caso contrario no podía permanecer en la aldea.

Este resumen de las normas de convivencia muestra lo instituido en la aldea. Tal carácter estaba dado porque quien lo instituía era el docente/director de la escuela: persona respetada, en tanto poseedor de conocimiento institucionalizado, y también querida por los lugareños.

La escuela rural de fines del siglo $\mathrm{XX}$ : los proyectos de los docentes

Hasta 1990 la escuela tenía dieciséis alumnos y dos docentes: directora y maestra. A partir de allí comienza un proceso de incremento de la matrícula que la llevó a un pico máximo de 71 alumnos en 2000, manteniéndose hasta la actualidad en alrededor de 60 alumnos.

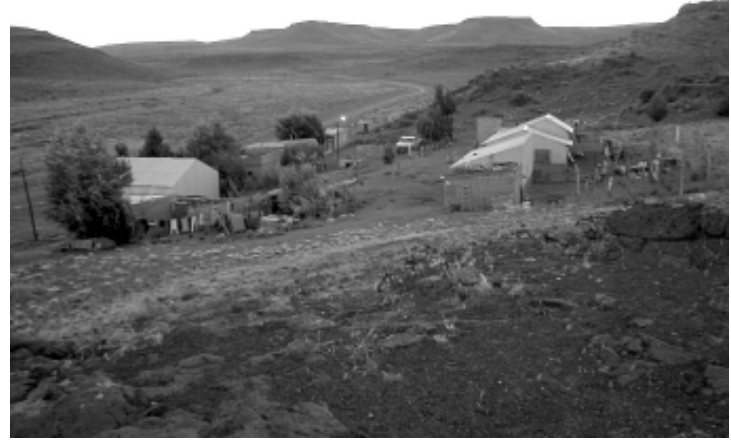

Foto 2. Vista del ordenamiento interno de Chacay Oeste 


\section{CUADERNOM::}

Escuelas ruRales y producción del espacio. Aldea escolar Chacay Oeste, Chubut

6- Tanto en distancia como en tiempo debido al estado de los caminos vecinales y a la falta de medios de movilidad, además del caballo.
Este proceso fue el resultado de acciones realizadas por los docentes en el marco de un proyecto claramente explicitado: educar a todos los niños residentes en el entorno. Incluso a aquellos que por vivir muy distantes ${ }^{6}$ debían recurrir a internados ubicados en ciudades que los alejaban de sus familias y de su lugar de origen.

Una de las primeras acciones fue una suerte de reconciliación de la escuela con algunos sectores de su área de influencia, por ejemplo Laguna Fría. Para ello el director junto a los docentes, al igual que en sus inicios, recorrieron unidades domésticas cercanas con el fin de modificar la situación que los llevó a no enviar más a sus hijos a esa escuela.

Estas acciones estaban fundadas en el objetivo de:

“...proyectarnos hacia el campo que era donde estaban los chicos. Algunos tenían posibilidades de ir a la escuela y otros estaban en los internados, salían todo el año. Y un poco la propuesta nuestra era que el chico pudiera recuperar, o sea si la gente estaba luchando por su espacio de tierra pudiera quedarse en el lugar y hacer la defensa. Porque de hecho el chico que salía a los internados, terminaba $7^{0}$ año y estaba totalmente desarraigado sin poder volver a su lugar, sin querer su lugar. Quedó dando vueltas en la periferia de la ciudad, y hoy es el que anda por ahí dando vueltas, digamos porque no tiene trabajo..." (ex docente de la escuela 63).

Si bien el objetivo era educar, en el relato aparece una intencionalidad que explicita el sentido de esa educación en su lugar de origen y no en un internado alejado de la cotidianidad. Es decir, en el relato del docente queda explícito que la educación no es neutral. Nos referimos al hecho concreto de la defensa de la tierra, tanto quedándose en el lugar como otorgando herramientas cognitivas que los ayuden a lograr el cometido. Un docente manifestaba esta situación de la siguiente manera:

“...se sabía para quién se trabajaba, se sabía para qué, a dónde tenía que apuntar la escuela. Se sabía para qué había que dar clases. Se generaron los primeros egresados del polimodal que en esa época no era polimodal rural arrancó siendo Educación y Trabajo después fue la EAS [Educación Abierta Semipresencial]... o sea se daban clases y se laburaba y sabíamos para dónde ir, eso estaba muy claro [...] desde lo ideológico...." (maestro rural). 


\section{Andrea Daniela Franco}

Escuelas RURALES Y PROdUCción del espacio. AldEA escolar Chacay Oeste, Chubut

De este modo, algunos padres, que ya tenían casa en la aldea, comienzan a enviar a sus hijos a la escuela de Chacay Oeste, generándose un período de recuperación de la matrícula.

El segundo momento fue la creación del albergue en 1995. Junto con esto comienza a funcionar un sistema de alternancia educativa ${ }^{7}$ de veinte días de clase seguidos por diez días de descanso. Las estadías alternadas en la escuela y en la casa contribuyeron a dinamizar la vida social y económica de las familias residentes en el área de influencia y que enviaban a sus niños allí. La alternancia facilitaba a los alumnos que estaban albergados el regreso a sus hogares para colaborar con sus padres en las tareas ganaderas como esquila, cría del ganado, etc. Este sistema había sido consensuado con las familias. Debe destacarse que la organización del trabajo en la explotación es fundamental para la subsistencia de la familia ya que los roles y actividades están distribuidos en función de la edad y del sexo.

Por otro lado, las actividades, tanto laborales como sociales que se realizan en el lugar, si se corresponden con sus proyectos, estarán auspiciadas y apoyadas por los docentes. O dicho de otro modo, los docentes promoverán aquellas actividades que contribuyan al logro de sus objetivos.

Por ejemplo, ha sido la escuela, en cierto momento histórico, la que incentivó y posibilitó el encuentro de los pobladores con el fin de generar algunos cambios productivos en sus establecimientos.

Como venimos diciendo, la escuela rural, mucho más que la urbana que compite con diferentes y variadas instituciones, tiene un rol insuperable como organizador y reproductor de todas las dimensiones sociales y, por ende, del territorio.

De hecho siempre ha dependido, casi exclusivamente del director, desde la permanencia de la escuela, ante los vaivenes de los diferentes gobiernos de turno ${ }^{8}$, hasta la posibilidad de desarrollo del lugar en el que actúa. Al respecto un docente señalaba:

"La escuela nuclea de alguna manera las necesidades de la gente. Si estás abierto, no te pueden pasar por encima, creo que la gente viene a plantear, que tiene problemas
7- Para un mayor desarrollo del tema ver Forni, Neiman, Roldán y Sabatino (1998) Haciendo escuela. Alternancia, trabajo y desarrollo en el medio rural. Ed. Cicccus. Bs. As.

8- En varias oportunidades se ha intentado cerrar los albergues de las escuelas ubicadas en las aldeas escolares con lo cual los niños cuyas familias no pueden asentarse en la aldea deberían asistir a internados ubicados en lejanas ciudades, con todas las consecuencias negativas que ello implica. 


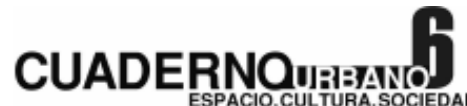

Escuelas ruRales y producción del espacio. Aldea escolar Chacay Oeste, Chubut

de tierra, o algo así. Si la escuela está abierta realmente debería ser el núcleo. Yo no digo, porque de hecho hay un poder, o sea, hay que ver cómo manejamos ese poder, y no cerrar los ojos ante las necesidades que uno está viendo..." (ex-docente de la escuela 63).

Entonces, la función de la escuela rural, más allá de lo pedagógico, es social.

“...Lo que pasa es que acá todas las demandas de la gente pasan por la escuela, y acá vemos adónde hay que derivarlo...es decir, en la escuela se trata de solucionar los problemas sobre la marcha..." (ex-directora de escuela rural en una aldea escolar)

“...La escuela pretende estar en cada familia...porque si el chico no está bien de salud, o no está bien asistido en lo social no podrá rendir en la escuela. Este es el objetivo de la escuela, coordinar las actividades..." (ex-directora de una escuela rural en una aldea escolar. Revista del Ministerio de Educación de la Provincia del Chubut; 1998: 33).

La directora de escuela rural de una aldea escolar, señalando el lugar donde se construirán viviendas para diez familias que vivían en condiciones de hacinamiento, decía:

“....El año que viene aumentará la matrícula ya que otras familias se instalarán en la aldea, eso tiene mucho que ver con la propuesta abierta que hemos hecho a la comunidad, nos pone muy felices y nos compromete más aún. Apoyados por Misiones Rurales Argentinas se instalará próximamente una familia compuesta por una mamá y tres chiquitos que presentan una problemática social importante y creen que la aldea les brinda el espacio natural y la contención afectiva que están buscando..." (ex directora de escuela rural en una aldea escolar) (Revista del Ministerio de Educación de la Provincia del Chubut; 1998).

Entre 1990 y 2000 se realizaron desde la escuela diferentes actividades vinculadas con el desarrollo del lugar. Por ejemplo, reuniones con distintos fines como: la venta de pelo y la 


\section{Andrea Daniela Franco}

Escuelas RURALES Y PROdUCción del espacio. AldEA escolar Chacay Oeste, Chubut

compra de mercadería (alimentos y ropa) en conjunto en la ciudad de Trelew. Esta situación puso de manifiesto un importante cambio en la forma de comercialización de los productos ganaderos. Es decir, una transitoria independencia de los productores respecto de las barracas y almacenes de ramos generales locales. Estas actividades eran manifestadas en una revista local elaborada por docentes y alumnos.

Otros motivos de reuniones han sido la reivindicación de su cultura y la participación en encuentros efectuados con otras escuelas, con organismos provinciales y con la comisión aborigen ${ }^{9}$. Estas reuniones fueron realizadas tanto en el edificio escolar como en unidades domésticas cercanas, pero siempre alentadas por los docentes.

Por último, interesa señalar que en este sentido la escuela comienza a vislumbrarse como defensora de los derechos y protectora de la identidad de los habitantes de su área de influencia. Así lo señaló un abogado que trabaja en la defensa de los derechos de las comunidades aborígenes:

“el vínculo con la escuela es muy importante en el caso de Fulanito. Es decir, él tiene varios hijos todos van a la escuela...la alternancia permitía ciertos vínculos... Empezó a aparecer el problema de que Fulanito no tenía título [de propiedad de la tierra]... tampoco tenía boleto de señales en el Juzgado de Paz. Entonces, tenía animales propios pero no los podía señalar con señal propia, lo cual lo perjudicaba en términos comerciales porque tenía que vender por un vecino como si fueran de otro, vender en negro por así decirlo, más barato".

Todas estas situaciones ponen en evidencia la intencionalidad de los docentes en cada una de las acciones generadas y/o acompañadas desde la institución.

\section{REFLEXIONES FINALES}

La escuela ha sido, y sigue siendo, un ámbito físico e institucional fundamental en la construcción del espacio rural. Dado que no sólo ha educado a cientos de niños sino que
9- Recordemos que muchos pobladores rurales son descendientes de las comunidades aborígenes de etnia mapuchetehuelche. 


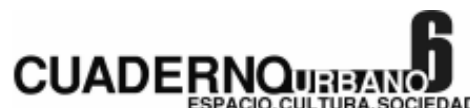

Escuelas ruRales y producción del espacio. Aldea escolar Chacay Oeste, Chubut

principalmente ha organizado, en torno de ella, a las comunidades rurales responsables de construir un modelo de ruralidad estable y rico en términos de vida social e identidad local. Modelo que tiene como actor principal a la familia de productores que viven en los campos.

De este modo, la escuela rural contribuye a mantener el poblamiento del lugar y a fortalecer su tejido social.

El rol del maestro, en tanto conductor de la escuela, ha sido y sigue siendo central en la producción del territorio. Ellos se han ocupado de buscar a los alumnos y hasta de colaborar con la construcción de las viviendas. También debían tener conocimientos de enfermería y actuar como mediadores en conflictos familiares y vecinales o ante injusticias perpetradas en perjuicio de los lugareños.

Los relatos de los maestros y pobladores son muy representativos. El docente, consciente o no de ello, pone en juego un proyecto ideológico al momento de enseñar. Aquellos que se limitan sólo a impartir los contenidos curriculares están adhiriendo al proyecto ideológico nacional. Si bien esto ocurre en todos los niveles, es más notable en las escuelas rurales donde la dinámica del lugar depende casi exclusivamente de ellos.

De este modo, la escuela rural es una potente herramienta para el desarrollo territorial. La toma de posición frente a los conflictos con la tenencia de la tierra y el interés por mantener en el campo a los más jóvenes abre un camino de esperanza para los espacios rurales patagónicos.

\section{BIBLIOGRAFÍA}

BANDIERI, Susana (2005) Historia de la Patagonia. Sudamericana. Buenos Aires BUSTOS CARA, Roberto (1998) "Espacio-tiempo y territorio" en Cernadas De Bulnes y Bustos Cara (1998) Estudios Regionales Interdisciplinarios .Ed. UNS. Bs. As.

FORNI, Neiman, Roldán y Sabatino (1998) Haciendo escuela. Alternancia, trabajo y desarrollo en el medio rural. Ed. Cicccus. Bs. As.

FRANCO, Daniela (2005) “La producción y re-producción del espacio rural en Chacay 


\section{Andrea Daniela Franco}

Escuelas RuRales y producción del espacio. Aldea escolar Chacay Oeste, Chubut

Oeste - Provincia del Chubut". Actas de las Iํo Jornadas de Antropología Rural "Desde el

Norte ...". Tucumán, del 23 al 25 de mayo de 2005. Publicado en CD.

MINISTERIO DE EDUCACIÓN DE LA PROVINCIA DEL CHUBUT (1998) Revista La transformación educativa. № 4 . Rawson-Chubut.

RODRÍGUEZ, LIDIA (1996) El análisis de lo institucional en la escuela. Un aporte a la formación autogestionaria para el uso de los enfoques institucionales. Notas teóricas. Paidós. Bs. As. -Barcelona-México. 
